\title{
Memories and Prevalence of Posttraumatic Stress Disorder in Intensive Care Units
}

\author{
Memórias e Prevalência de Transtorno de Estresse Pós-Traumático \\ em uma Unidade de Terapia Intensiva
}

\author{
Karla Bender Rovatti ${ }^{*}, a$, Maycoln Teodoro ${ }^{b} \&$ Elisa Kern de Castro ${ }^{c}$ \\ ${ }^{a}$ Hospital Mãe de Deus, Porto Alegre, Brasil, ${ }^{b}$ Universidade Federal de Minas Gerais, Belo Horizonte, Brasil \\ \& ${ }^{c}$ Universidade do Vale do Rio dos Sinos, São Leopoldo, Brasil
}

\begin{abstract}
The present study evaluated the prevalence of PTSD indicators in patients who had to be hospitalized in ICU six months after being discharged and examined the relationship between PTSD and mnemonic memories. Participants were 41 adult patients with different diseases who answered questionnaires about PTSD, memory and clinical information. It was identified that $24.4 \%$ of the sample presented PTSD symptoms. These patients presented more affective memories than those without PTSD $(t=2.29, p<.05)$. Affective memories correlated with total PTSD and with the dimensions 'reliving' $(r=.443, p<.01)$ and 'excitability' $(r=.403, p<.01)$. Hierarchical regression analysis showed that sex (woman) and the presence of affective memories were PTSD predictors, explaining $38.2 \%$ of the variance.

Keywords: Intensive care units, memory, posttraumatic stress disorder, quality of life.

Resumo

$\mathrm{O}$ estudo avaliou a prevalência de indicadores de TEPT em pacientes que foram internados em UTI seis meses após a alta hospitalar, e examinou a relação entre TEPT e recordações mnêmincas. Participaram 41 pacientes adultos com diferentes doenças, que responderam a questionários sobre TEPT, memórias e informações clínicas. Identificou-se que $24,4 \%$ da amostra possuía indicadores de TEPT. Estes pacientes apresentaram mais memórias afetivas que os pacientes sem TEPT $(t=2,29, p<0,05)$. As memórias afetivas correlacionaram-se com o TEPT total $(r=0,408, p<0,01)$ e com suas dimensões revivência $(r=0,443, p<0,01)$ e excitabilidade $(r=0,403, p<0,01)$. A análise de regressão hierárquica mostrou que o sexo (mulher) $(\beta=0,44$, $p<0,01)$ e a presença de memórias afetivas $(\beta=0,46, p<0,01)$ foram preditoras de TEPT, explicando $38,2 \%$ da sua variância.

Palavras-chave: Unidades de terapia intensiva, memória, transtorno de estresse pós-traumático, qualidade de vida.
\end{abstract}

Admission to an intensive care unit (ICU) is often sudden, unexpected, bringing great risk to the continuity of life. Victims of many accidents or diseases that until recently were considered fatal, today with technological advancements in medical science and increasingly sophisticated ICUs, have eluded the risk of death (Knobel, P. B. A. Andreoli, \& Erlichaman, 2008).

\footnotetext{
"O trabalho é parte da dissertação de mestrado de Karla Bender Rovatti, apresentado no Pós-Graduação em Psicologia da Universidade do Vale do Rio dos Sinos (UNISINOS).

Os autores agradecem ao Hospital Mãe de Deus pelo apoio financeiro e de recrutamento de pacientes para a realização da pesquisa.

Endereço para correspondência: Programa de PósGraduação em Psicologia, Centro de Ciências da Saúde, UNISINOS, Av. Unisinos, 950, Bairro Cristo Rei, São Leopoldo, RS, Brasil 93022-000. E-mail: akrovatti@gmail.com
}

In this context marked by high technology, evidencebased medicine carried out by highly qualified teams in different areas of scientific knowledge have sought to learn more about and in greater quality the impact caused by the art of survival. On one side are the drugs, the rapid and unexpected answers from doctors, the curing of the disease and the pursuit of survival, on the other, are the patients, the struggle, fear, isolation, the sounds, the groans of pain (Scliar, 1996).

Some Brazilian studies (Bittencourt et al., 2007; R. A. S. Dantas \& Marosti, 2006) point to the need for health professionals to identify the existing stressors found in the ICU, as they may contribute to the onset of psychological disorders and affective stress reactions atypical or chronic, and psychopathology. The stressors most commonly found in this environment are: the state of confusion or delirium, anxiety, depression and posttraumatic stress disorder. 
It is in this sense that post-traumatic stress disorder (PTSD) has been studied in hospital settings, preferably in critical areas such as emergency and intensive care due to the emotional consequences, the memories of being hospitalized and the suffering reported by the patient after an ICU experience (Capuzzo et al., 2008; Löf, Ahlströn, \& Berggren, 2006; Ringdal, Plos, Lundberg, Johansson, \& Bergbom, 2009; Roberts, Rickard, Rajbhandari, \& Reynolds, 2007). PTSD is considered an anxiety disorder precipitated by a trauma and its development is associated with an external traumatic event source (Kristensen, 2005). According to the Diagnostic and Statistical Manual of Mental Disorders (American Psychiatric Association, 2002), the diagnosis is presented as an expected response before a traumatic event, characterized by a set of secondary reactions that persist for the patient. PTSD appears to have a high prevalence in Brazil and is associated with traffic accidents and urban violence (Figueira \& Mendlowics, 2003), however, has always been underdiagnosed in the population that suffers from other types of trauma.

From the cognitive perspective, PTSD can be understood as a memory disorder, being that the patients are irrevocably tied to memories of the traumatic past, undermining the prospects for his or her future and that of the people living with the victim of the trauma (McNally, 1998). Its clinical diagnosis depends on the period, the duration and onset of symptoms. It is considered acute PTSD when symptoms occur within the window of more than a month after the event and less than three months; it is considered chronic PTSD if symptoms occur more than three months after, and delayed PTSD when symptom onset begins six months after the trauma (Breslau, Chase, \& Anthony, 2002; Yehuda \& McFarlane, 1995).

Several international studies show that the prevalence of PTSD is high, ranging from $8 \%$ (Samuelson, Lundberg, \& Fridlund, 2007) to 64\% (J. Griffiths, Fortune, Barber, $\&$ Young, 2007). Such differences may be attributed to the different instruments used to measure PTSD. However, there is a consensus among researchers about the risk factors for the development of symptoms (Cuthebertson, Stracham, \& Seatt, 2003; Girard et al., 2007; Rattray, Johnston, \& Wildsmith, 2005; Schelling, 2008; Scragg, A. Jones, \& Fauvel, 2001), such as being female, going through psychological agitation in the ICU, being restrained mechanically, stopping benzodiazepines during hospitalization, use of opioids for sedation, septic shock, delirium, hypoxia, mechanical ventilation time and prior psychopathology. In these studies, there were no factors that could offer hope of being risk factors such as severity and complexity of neither illness nor hospitalization time. However, other studies point out that frightening or traumatic memories (Davydow, Gifford, Desai, Needham, \& Bienvenu, 2008) along with the presence of delusional memories along with the absence of recalling the admission to the ICU and discharge to the general ward may also contribute to the appearance of PTSD (Ringdal et al., 2009; Samuelson et al., 2007; Schelling, 2008).

There are limitations to the assessment of the prevalence of PTSD in ICU patients due to the lack of followup after hospital discharge (Schelling, 2008; Twigg, Humphris, Jones, Bramwell, \& R. D. Griffiths, 2008). Therefore, the aim of this study is to identify indicators of the prevalence of PTSD in a sample of patients who were hospitalized in an ICU of a private hospital in Rio Grande do Sul and examine the relationship between PTSD and mnemonic memories of experiences in the ICU six months after the hospital discharge. In addition, we sought to identify the predictive value of the memories (delusional or traumatic, affective memories and factual memories) reported by patients regarding the ICU environment for the emergence of symptoms of posttraumatic stress in these patients.

\section{Method}

\section{Participants}

The study included 41 patients who survived a highly complex ICU hospitalization in a private general hospital in Porto Alegre-RS. Of the total sample, 18 were females and 23 males, aged between 22 and 79 years (mean $=56.09$ years, $S D=14.80)$. The mean days of ICU stay was 19.15 days $(S D=22.31)$. This sample accounted for $25.78 \%$ of all patients admitted to the the hospital's ICU six months before the completion of data collection for this study (August-October 2009). Of the total 342 patients who were admitted to the ICU in the period, 64 died, 119 did not fit the inclusion criteria (described below), with a remaining 159 patients being eligible for the study. Of these 159 patients, 118 did not participate: 23 refused to participate, 58 had some physical or psychological morbidity after hospitalization and 37 patients were not found. Patients were selected from a list provided by the Hospital's ICU, noting the time of hospitalization and degree of complexity in accordance with the APACHE II score as the criteria (See Instruments).

As an inclusion criterion for this study, we included patients with an ICU stay of more than 48 hours and being older than 18 years of age. The exclusion criteria was considered to be: patients with low vision and hearing loss, degenerative neurological disease or dementia, terminal cancer disease, prior psychiatric condition and / or were under the use of psychotropic medications.

Regarding the admission diagnosis, 14 were admitted to the ICU because they had a cardiological diagnosis, eight patients had a clinical diagnosis, eight with a neurological diagnosis, five patients with respiratory problems, three for trauma, one surgical patient and one oncology. Table 1 shows the main socio-demographic and clinical variables of the sample. 
Table 1

Socio-Demographic and Clinical Variables

\begin{tabular}{|c|c|c|}
\hline Variables & & $N(\%)$ \\
\hline Gender & $\begin{array}{l}\text { Male } \\
\text { Female }\end{array}$ & $\begin{array}{l}23(56.1 \%) \\
18(43.9 \%)\end{array}$ \\
\hline Marital Status & $\begin{array}{l}\text { Single / separated / widowed } \\
\text { Married }\end{array}$ & $\begin{array}{l}16(39.0 \%) \\
25(61.0 \%)\end{array}$ \\
\hline Education & $\begin{array}{l}\text { To fund education. complete } \\
\text { Until high school } \\
\text { Until more complete } \\
\text { Graduation }\end{array}$ & $\begin{array}{l}07(12.2 \%) \\
14(34.2 \%) \\
13(31.7 \%) \\
09(21.9 \%)\end{array}$ \\
\hline Medical Specialties & $\begin{array}{l}\text { Cardiology } \\
\text { Neurology } \\
\text { Pulmonology } \\
\text { General Practice } \\
\text { Surgery. } \\
\text { Trauma } \\
\text { Oncology }\end{array}$ & $\begin{array}{r}14(36.5 \%) \\
08(20 \%) \\
05(12.5 \%) \\
08(20 \%) \\
01(2.5 \%) \\
03(7.5 \%) \\
01(2.5 \%)\end{array}$ \\
\hline Use of Mechanical Ventilation & $\begin{array}{l}\text { Yes } \\
\text { Not }\end{array}$ & $\begin{array}{l}22(53.7 \%) \\
19(46.3 \%)\end{array}$ \\
\hline Use of Sedation & $\begin{array}{l}\text { Yes } \\
\text { Not }\end{array}$ & $\begin{array}{l}24(58.5 \%) \\
17(41.5 \%)\end{array}$ \\
\hline Use of Mechanical Restraint & $\begin{array}{l}\text { Yes } \\
\text { Not }\end{array}$ & $\begin{array}{l}11(26.8 \%) \\
30(73.2 \%)\end{array}$ \\
\hline Agitation in the ICU & $\begin{array}{l}\text { Yes } \\
\text { Not } \\
\text { Unregistered }\end{array}$ & $\begin{array}{r}10(24.4 \%) \\
30(73.2 \%) \\
01(2.4 \%)\end{array}$ \\
\hline Disease Preview & $\begin{array}{l}\text { Yes } \\
\text { Not }\end{array}$ & $\begin{array}{l}27(65.9 \%) \\
14(34.1 \%)\end{array}$ \\
\hline Episode of Delirium in the ICU & $\begin{array}{l}\text { Yes } \\
\text { Not } \\
\text { Unregistered }\end{array}$ & $\begin{array}{r}11(26.8 \%) \\
26(63.4 \%) \\
04(9.8 \%)\end{array}$ \\
\hline Presence of Social Support & $\begin{array}{l}\text { Yes } \\
\text { Not }\end{array}$ & $\begin{array}{r}40(97.6 \%) \\
01(2.4 \%)\end{array}$ \\
\hline Katz Index & $\begin{array}{l}\text { It is independent. } \\
\text { Assistance } \\
\text { Dependent }\end{array}$ & $\begin{array}{r}35(85.4 \%) \\
05(12.2 \%) \\
01(2.4 \%)\end{array}$ \\
\hline Degree of Complexity of Disease & $\begin{array}{l}\text { HIGH } \\
\text { Mean } \\
\text { Low }\end{array}$ & $\begin{array}{c}13(31.7 \%) \\
17(41.5 \%) \\
11(26.8 \%)\end{array}$ \\
\hline Mean $(S D)$ & $\begin{array}{l}\text { Age (years) } \\
\text { ICU Length of Stay (days) }\end{array}$ & $\begin{array}{l}56.9(14.8) \\
19.5(22.4)\end{array}$ \\
\hline
\end{tabular}

\section{Instruments}

Socio-Demographic and Clinical Variables Data Sheet. We sought information regarding clinical and sociodemographic data of patients admitted between August and October 2009. We included data about the patient (name, sex, age, date, education, occupation and marital status, social support) as well as issues related to the illness. The clinical data encompassed the ICU diagnosis at discharge, presence or absence of mechanical ventila- tion (MV), sedation (S) and mechanical restraint (CM), and some clinical data described in the medical records relating to being emitted to the ICU, such as agitation, prior psychiatric illness, disease or comorbidity, prior episode of delirium, etc.

Katz Index - Inventory of Activities of Daily Living (Gallo, Reichel, \& Andersen, 1995). Investigates the patient's functional capacity (bathing, dressing, using the phone, manage finances, housekeeping, and other more 
complex activities). The inventory has three scores for each of the items, according to the level of patient dependency: Independent / needs assistance / dependent. The Katz Index was originally published by Katz, Ford, Moskowitz, B. A. Jackson, and Jaffe (1963), and adapted by Gallo et al. (1995). It was recently translated into Portuguese by Marcia Scafuzca (forthcoming release unpublished).

Acute Physiology and Chronic Health Evaluation ([APACHE II], Knaus, Draper, Wagner, \& Zimmerman, 1985). A prognostic index criterion for admission and discharge from the ICU that provides a scientific description and quantity of ICU patients. This indicator provides the intensive care physician with useful information for the performance analysis of patients from the same group, numerically defining their severity, indicating an approximate predictor of the rate of mortality, as well as the profile of an ICU. The score is calculated from the routine measurements of physiological parameters such as blood pressure, body temperature, heart rate, among others, during the first 24 hours after admission to intensive care. The calculation method is optimized for the role, and the resulting score should be interpreted by the attending intensive care physician regarding the patient's illness and the clinical signs predicting the degree of complexity (high, medium, low) for treatment and the possibility of death. This study considered the APACHE II score for the first 24 hours after the patient's admission to the ICU, as reported in the medical records.

Memory Tool (C. Jones, Humphris, \& R. D. Griffiths, 2000). Investigates the memories of patients admitted to intensive care about the ICU's environment, after the recovery period. It contains 14 questions and answers with the patients classifying the memory as clearly / vaguely / nothing (do not remember), with other questions being answered in yes / no format. In addition, some questions are presented with an alternative for open response. The Memory Tool separates the memories into three types: delusional memories or traumatic (derived from dreams, nightmares, hallucinations, feeling that people wanted to hurt you), factual memories (memories of the mouth and nose tube, family, aspirations and medical visits) and the affective memories (memories of feelings such as despair, fear, depression, anxiety and pain). The Memory Tool cannot be added in order to obtain an overall score, while the individual items developed to evaluate types of memories (delusional, affective, factual) are also not interconnected, therefore they cannot be considered parts of the same domain. In the present study, we used the version translated from English into Portu-guese by Granja et al. (2008).

Screen for Posttraumatic Stress Symptoms ([SPTSS17], Carlson, 2001 adapted). Investigates the symptoms of posttraumatic stress disorder. It consists of 17 items in which the patient rates, on a scale of zero (never had the experience) to 10 (it was always going on) experiences or events that occurred in recent weeks or months of his or her life. Allows for the evaluation of three major symptoms of PTSD: (B) reliving or re-experience, (C) avoidance or numbing and (D) increased arousal. The Portuguese version was made by Kristensen (2005). The indexes of the present study ( $\alpha=.92)$ were higher than the psychometric properties of the original study $(\alpha=.85)$.

\section{Design and Procedures for Research and Ethics}

Data collection was performed with patients who were in a 32 bed ICU for critically ill patient care, which attends a monthly average of 114 patients.

The procedures used for data collection and data analysis followed the project specifications approved by the Institution's Ethics Committee ([CEP], protocol \# 09/ 293d, cover No 255368 30/06/2009).

It was carried out together with the gathering of the hospital documents of the patients admitted from August to October 2009. These were separated by complexity, respecting the criteria for inclusion and exclusion, while searching for clinical variables in the patient's score. As per the identification of potential participants, a telephonic approach was adopted and upon the acceptance of the patients to participate in the survey, a date was scheduled, as well as time and place for signing the ICF (Informed Consent Form) and data collection. Most patients (20) completed the questionnaires in a private room in the hospital's central reception area, away from the ICU. Seven patients preferred to respond to the instruments in their homes, six preferred that the instruments were mailed and eight patients completed the instruments in a hospital room, with chairs arranged in a classroom format. The researcher explained the research at hand, ensuring that each patient had the right to withdraw at any time from the study or to not participate at all.

\section{Statistical Analysis}

All data from the research protocols were collected and tabulated in the database of the Statistical Package for Social Sciences (SPSS) 18.0. Initially, we performed analysis of the psychometric properties of each instrument. The following descriptive analysis was performed (mean, standard deviation, percentages) on the overall results. To analyze the associations between variables, correlations were made between the variables of interest (Pearson) and comparison of means (student's $t$-test and ANOVA). We performed linear regression analysis to establish the predictive model for the PTSD variable.

\section{Result}

Initially, analysis was performed on the percentage of patients with symptoms of PTSD and without PTSD symptoms six months after discharge, using a cutoff of $>$ 5 based on the average of each patient in the SPTSS instrument, as suggested in Kristensen (2005). By this method, it was possible to detect symptoms compatible with PTSD in $24.4 \%$ of the sample or 10 patients. 
Then the sample was divided into two groups - patients with and without PTSD symptoms - and the mean test comparison was carried out (student's $t$-test) to examine possible differences in the types of memories between them. It was observed that patients with PTSD symptoms had significantly greater affective memories on average than patients without symptoms $(T=2.290, p<.05)$.

To compare indicators of PTSD to the means of the memory types in relation to the degree of complexity of the patients (low, medium and high), we performed variance analysis (ANOVA).There were no significant differences between groups.

The Pearson correlation analysis between PTSD and its dimensions (re-experiencing, avoidance and increased arousal), memories, and its dimensions (emotional, factual, delusional), patient age and hospital stay in days showed that only the affective memories were significantly correlated with the PTSD total $(R=.408, p<.01)$ and with the reliving dimensions $(R=.443, p<.01)$ and arousal $(R=.403, p<.01)$. Age showed no significant correlation with any of the psychological variables investigated. The days of hospitalization were significantly associated with delusional memories $(R=.461, p<.01)$.

Finally, we performed hierarchical regression analysis in order to verify the predictive power of affective memories for PTSD symptoms, controlling for gender of participants, based on the results of correlation analysis (Table 2). It can be seen in the first step of the analysis, that gender was a significant predictor of PTSD $(\beta=.43$, $p<.01$ ), explaining $18.2 \%$ of the variance. In the second step, with the inclusion of the affective memories variable, both gender as well as affective memories proved to be predictive of PTSD, in a significant way $(\beta=.47, p<.01$ and $\beta=.45, p<.01$ respectively), explaining $38.2 \%$ of the total variance.

Table 2

Linear Regression: Total PTSD

\begin{tabular}{lcc}
\hline & Step 1 $(\beta)$ & Step 2 $(\beta)$ \\
\hline Gender & $.43 * *$ & $.47 * *$ \\
Affective Memories & - & .45 \\
$\Delta \mathrm{R}^{2}$ & .18 & .20 \\
Two $\mathrm{R}$ & .18 & $.38 * *$ \\
\hline
\end{tabular}

$* p=.05 ; * * p=.01$.

\section{Discussion}

This study investigated the prevalence of PTSD in ICU patients six months after discharge, based on the memories of the experiences reported involving these patients during the ICU stay. The prevalence of $24.4 \%$ of patients with indicators of PTSD shows that these ratios are within the margin referred to in the international literature, which is ample, reaching 64\% (Samuelson et al., 2007), and also very close to rates found in the systematic review of Caiuby, P. B. A. Andreoli e Andreoli (2010) on PTSD in patients who were hospitalized in intensive care, which was $17-30 \%$.

The presence of higher levels of affective memories in PTSD patients compared to patients without PTSD, and their ability to be predictive of PTSD in this sample confirms its importance for this group of patients. C. Jones, R. D. Griffiths, Humpris and Skirrow (2001) had already demonstrated the role of delusional or traumatic memories in the prediction of PTSD, while the factual memories serve as protective factors for these patients, but had not found data on affective memories. According to these authors, becoming delirious during the period of hospitalization would generate a loss of contact with the reality experienced during this period, leaving a space for the absence of memories, or even the presence of false memories (Loftus, 2003). These could cause the patient to have the need to constantly seek for information about their experience, not permitting an understanding, representation and memory consolidation. Thus, the absence of factual memories could stand as a strong risk factor for the consolidation of traumatic memories or false memories, which contributes to the onset of PTSD.

The importance of affective memories in terms of PTSD found in this study, such as fear, panic, anxiety and pain, can be understood from the uncertainty regarding their health and survival that the ICU environment brings with it. The patient begins to feel vulnerable, insecure, anxious and sometimes panicky, showing lack of control over oneself and one's life (Novaes, Aronovich, Ferraz, \& Knobel, 1997). For Lemos and Rossi (2002), the physical environment, the distribution of resources, lighting and especially the mode of being a closed unit, without the presence of the family, with different and strange people at every turn, reinforces the idea of the patient, that this unknown place - where people are dying - is harmful, highly stressful and dreaded. The flow of strangers caused by shift changes and the number of professionals is large, which can often affect the patient's psychic organization when your body is completely disorganized.

The significant correlation found between the duration of ICU stay and delusional memories corroborates data from other studies that found a correlation between the probability of patients developing delirium and the consolidation of traumatic memories or delusions (D. L. Jackson, Proudfoot, Cann, \& Walsh, 2010; Samuelson et al., 2007). In turn, these associations functioned as precipitating the onset of PTSD (Capuzzo et al., 2004, C. Jones et al., 2003; Ringdal et al., 2009; Samuelson et al., 2007), which did not occur in this study. It should be noted that a state of confusion or delirium is a psycho-organic syndrome that affects many patients hospitalized in serious condition in the ICU. For Ely, Shintani, Speroff, and Gordon (2004), delirium presents a floating course and start and is responsible, in the ICU for generating emotional instability in patients and family functioning as a predictor of mortality within two years after patient's 
discharge from the ICU. It is seen as, by the same authors, as a common event in the ICU, even though it remains, like PTSD, underdiagnosed and trivialized by health teams. Therefore, the delirium may generate in the patient's mnemonic record of frightening memories, of persecutory content, consolidating and strengthening in an individual and his or her family, the idea that the intensive care environment is threatening, novice and traumatic.

This research study has facilitated the understanding of the psychological repercussions of the patient who has been admitted to the ICU from the memories of their experience. Based on the results collected, it will be possible to facilitate a network of conversations, actions, programs and healthcare policies to assist the intra-hospital team to understand the emotional and behavioral consequences precipitated by severe disease and the intensive care setting. To assess early risk factors and protection, stimulating interdisciplinary preventive strategies for PTSD, developing treatment plans and prevention in the intensive care setting should be goals to be achieved by interdisciplinary teams in the ICU.

The evaluation of the patient six months after their ICU stay can make important contributions to the development of interventional practices within the ICU environment. Having the knowledge that female patients and those with less affective memories are more likely to develop PTSD may point toward changes in the healthcare process related to family visiting hours within the ICU, for example. Currently in Brazil, there are few ICUs that provide extended visiting hours for family members. Due to illness, the closest people, capable of helping patients to react to the disease are blocked from having contact with the seriously ill patient. Knowing that the presence of family members can be one of the protective factors may contribute to a change in the current paradigm, which harmfully limits the family, the routine, structure, nursing staff, doctors and even the patient (Orlando, 2002).

The present study has some limitations, as the small number of patients and the fact that the diseases that led to ICU admission are heterogeneous. Moreover, the crosssectional and retrospective design made it impossible to collect data on the psychological aspects of patients during the ICU stay. However, the findings of this study are promising and give clear indications about the risk factors for PTSD. Future longitudinal studies will clarify the course of PTSD in these patients and foster increased understanding of the subject.

\section{References}

American Psychiatric Association. (2002). Diagnostic and statistical manual of mental disorders: DSM-IV-TR. Porto Alegre, RS: Artmed.

Bittencourt, A. G. V., Neves, F. B. C. S., Das, M. P., Albuquerque, L. C., Melo, R. M. V., \& Almeida, A. M. (2007). Analysis of stress for the patient in the intensive care unit. Journal of Intensive Care, 19, 53-59.
Breslau, N., Chase, G. A., \& Anthony, J. C. (2002). The uniqueness of the DSM definition of post-traumatic stress disorder: Implications for research. Psychological Medicine, 32, 573-576.

Caiuby, A. V. S., Andreoli, P. B. A., \& Andreoli, S. B. (2010). Disorder, posttraumatic stress disorder in patients of intensive care unit. Journal of Intensive Care, 22, 77-84.

Capuzzo, M. S., Bertacchini, S., Jones, C., Griffiths, A., Ambrosio, M., Bondanelli, R., et al. (2008). Patients with PTSD after intensive care Avoid hospital contact at 2year follow-up. Acta Anaesthesiologica Scandinavica, 52, 313-314.

Capuzzo, M., Valpondi, V., Cingolani, E., De Luca, S., Gianstefani, G., Grassi, L., et al. (2004). Application of the Italian version of the Intensive Care Unit Memory tool in the clinical setting. Critical Care Medicine, 8, 48-55.

Carlson, E. B. (2001). Psychometric study of a brief screen for PTSD: Assessing the impact of multiple traumatic events. Assessment, 8, 431-441.

Cuthebertson, B. H., Stracham, M., \& Seatt, J. (2003). Posttraumatic stress disorder after critical illnes requiring general intensive care. Intensive Care Medicine, 30, 450-455.

Dantas, R. A. S., \& Marosti, C. A. (2006). Evaluation of patients about the stressors in a coronary care unit. Acta Paulista Nursing, 19, 190-195.

Davydow, D. S., Gifford, J. M., Desai, S. M., Needham, D. M., \& Bienvenu, O. J. (2008). Posttraumatic stress disorder in general intensive care units survivors: A systematic review. Psychiatric General Hospital, 30, 421-434.

Ely, W. E., Shintani, B., Speroff, T., \& Gordon, S. M. (2004). Delirium as a predictor of mortality in mechanically ventilated patientes in the intensive care unit. Jama, 291, 1753-1762.

Figueira, I., \& Mendlowicz, M. (2003). Diagnosis of the disorder, posttraumatic stress disorder. Journal of Psychiatry, $25,12-16$.

Gallo, J. J., Reichel, W., \& Andersen, L. M. (Eds.). (1995). Handbook of geriatric assessment. Gaithersburg, MD: Aspen.

Girard, T. D., Shintani, A. K., Jackson, J. C., Gordon, S. M., Pun, B. T., Henderson, M. S., et al. (2007). Risk factors for post-traumatic stress disorder Symptoms Following critical illness requiring mechanical ventilation: A prospective cohort study. Critical Care, 11, 118-128.

Granja, C., Gomes, E., Amaro, A., Ribeiro, O., Jones, C., Carneiro, A., et al. (2008). Understanding posttraumatic stress disorder-related Symptoms after critical care: The early illness amnesia hypothesis. Critical Care Medicine, 36, 2801-2809.

Griffiths, J., Fortune, G., Barber, V., \& Young, J. D. (2007). The prevalence of posttraumatic stress disorder in survivors of ICU treatment: A Systematic Review. Intensive Care Medicine, 33, 1506-1518.

Jackson, D. L., Proudfoot, C. W., Cann, K. F., \& Walsh, T. (2010). A Systematic Review of the impact of sedation practice in the ICU on resource use, costs and patient safety. Critical Care, 14, R59.

Jones, C., Griffiths, R. D., Humphris, G., \& Skirrow, P. M. (2001). Memory, delusions, and the development of acute posttraumatic stress disorder-related Symptoms after intensive care. Critical Care Medicine, 29, 573-580.

Jones, C., Humphris, G., \& Griffiths, R. D. (2000). Preliminary validation of the ICUM: A tool for assessing memory of the intensive care experience. Clinical Intensive Care, 11, 251-255. 
Jones, C., Twigg, E., Lurie, A., McDougall, M., Heslett, R., Hewitt-Symonds, M., et al. (2003). The challenge of diagnosis of stress reactions following intensive care and Early Intervention: A review. Clinical Intensive Care, 14, 83-89.

Katz, S., Ford, A. B., Moskowitz, R. W., Jackson, B. A., \& Jaffe, M. W. (1963). Studies of illness in the aged. The index of ADL: A standardized measure of biological. Jama, 21, 914-919.

Knaus, W. A., Draper E. A., Wagner D. P., \& Zimmerman J. E. (1985). APACHE II: A severity of disease classification system. Critical Care Medicine, 13, 818-829.

Knobel, E., Andreoli, P. B. A., \& Erlichaman, M. (2008). Psychology and humanization: Assistance to critically ill patients. New York: Atheneu.

Kristensen, C. H. (2005). Posttraumatic stress disorder: Cognitive functioning and symptomatology. (Unpublished doctoral dissertation). Postgraduate Course in Developmental Psychology, Federal University of Rio Grande do Sul, Porto Alegre, RS.

Lemos, R. C. A., \& Rossi, L. A. (2002). The cultural meaning attributed to the intensive care unit by clients and their families: A link between the edge and freedom. Latin American Journal of Nursing, 10, 345-357.

Löf, L., Berggren, L., \& Ahlströn, G. (2006). Severely ill ICU Patients recall of factual events and unreal Experiences of hospital admission and ICU stay -3 and 12 months after discharge. Intensive \& Critical Care Nursing, 22, 154-166.

Loftus, E. (2003). Make-believe memory. American Psychologist, 58, 864-873.

McNally, R. J. (1998). Experimental approaches to cognitive abnormality in posttraumatic stress disorder. Clinical Psychology Review, 18, 971-982.

Novaes, M. A., Aronovich, A., Ferraz, M. B., \& Knobel, E. (1997). Stressors in ICU: Patients evolution. Intensive Care Medicine, 23, 1282-1285.

Orlando, J. M. (2002). ICU: Beyond technique: Humanization and art intensive care. New York: Atheneu.

Rattray, J. E., Johnston, M., \& Wildsmith, J. A. (2005). Predictors of emotional outcomes of intensive care. Anaesthesia, 60, 1085-1092.

Ringdal, M., Plos, K., Lundberg, D., Johansson, L., \& Bergbom, I. (2009). Outcome after injury: Memories, health-related quality of life, Symptoms of anxiety and depression after intensive care. The Journal of Trauma, 66, 1226-1233.

Roberts, B. L., Rickard, C. M., Rajbhandari, D., \& Reynolds, P. (2007). Factual memories of ICU: Recall at two years' post-discharge and comparison with delirium status During ICU admission - A multicentre cohort study. Journal of Clinical Nursing, 16, 1669-1677.

Samuelson, K. A., Lundberg, D., \& Fridlund, B. (2007). Stressful Experiences in relation to depth of sedation in mechanically ventilated Patients. Critical Care Nursing, 12, 93-104.

Schelling, G. (2008). Post traumatic stress disorder in somatic disease: Lessons from critically ill Patients. Progress in Brain Research, 167, 229-237.

Scliar, M. (1996). The passion transformed: History of Medicine in Literature: Vol. 2. São Paulo, SP: Companhia das Letras.

Scragg, P., Jones, A., \& Fauvel, N. (2001). Psychological problems Following ICU treatment. Anaesthesia, 56, 9-14.
Twigg, E., Humphris, G., Jones, C., Bramwell, R., \& Griffiths, R. D. (2008). Use of a screening questionnaire for posttraumatic stress disorder (PTSD) on a sample of UK ICU patients. Acta Anaesthesiologica Scandinavica, 52, 202-208.

Yehuda, R., \& McFarlane, A. C. (1995). Conflict between current knowledge about posttraumatic stress disorder and its original conceptual basis. American Journal of Psychiatry, 152, 1705-1713. 